\title{
DEVELOPING A TECHNOLOGY INTELLIGENCE STRATEGY TO ACCESS KNOWLEDGE OF INNOVATION CLUSTERS
}

\section{Authors:}

\author{
Rani J. DANG, Letizia MORTARA, Ruth THOMSON and Tim MINSHALL
}

\begin{abstract}
Current times are characterised by a knowledge-based economy and fast technological change. In this difficult environment, companies compete to maintain a relevant position through innovation. In response to these challenges, many companies are currently adopting an open approach to innovation, pursuing innovation by combining internal and external resources. Technology intelligence (TI) activities support the implementation of open innovation with the systematic capture and delivery of information about threats and opportunities arising from new developments in science and technology. A popular choice for TI is to establish 'listening posts' in areas of intense innovative activities, for example in regional clusters where technical information flows are known to be particularly intensive. In fact, literature suggests that in clusters vertical interactions along the value chain and horizontal interactions between competing companies help companies to capture the regional market trends and preferences and take relevant decisions concerning their future technological focus. As companies cannot afford to setup a technology outpost in every single geographic area where innovation and technological development are intense and relevant, they need to develop a TI strategy to explore remotely the science and technology that is being developed across long geographic distances. This chapter illustrates through a detailed case study of Kodak European Research (KER), how companies can organise and implement $\mathrm{Tl}$ activities to leverage the knowledge and existence of regional clusters. It integrates two domains of research on $\mathrm{Tl}$ and regional clusters, giving insights into how $\mathrm{Tl}$ activities are strongly influenced by location. Through the experience of KER, this chapter explores i) the pros and cons of becoming embedded within a cluster to take part in the 'local buzz'; ii) the strategy to access knowledge of other clusters; iii) the communication strategy to manage the TI activity within and outside of the cluster.
\end{abstract}




\section{Profile of Authors}

Rani Jeanne DANG is a Doctoral Researcher in Management at CNRS, (GREDEG Management Department, University of Nice Sophia-Antipolis, France). Her main research interest is Knowledge Management in regional clusters. Currently she studies the process of SMEs' insertion into innovation projects within regional clusters by examining the micro foundations of territorial innovation dynamics. Her research is conducted in partnership with a pôle de compétitivité: The "Pôle SCS". Rani is also a Visiting Researcher at the Centre for Technology Management at the IfM, University of Cambridge (UK) in 2008 and 2010.

Dr Letizia Mortara is a Research Associate at the Centre for Technology Management at the Institute of Manufacturing, University of Cambridge (UK) since 2005. Her current research interests include open innovation and technology intelligence. Prior to joining IfM Letizia gained a Degree in Industrial Chemistry at the University of Bologna in Italy. After spending three years working as a Process/Product Manager in a chemical industry, she moved to the UK where she gained her PhD in Processing and Process Scale-up of Advanced Ceramic Materials at Cranfield University.

Ruth Thomson was the Innovations Leader of Kodak European Research, Cambridge (UK) from Jan 2006 until June 2009. In this role Ruth established the Open Innovation and Technical Intelligence strategies for the centre and established mechanisms and tools that helped the team to identify and progress external 'ideas' and technology leads from across the European region. Ruth now works as a Business Development Consultant at Cambridge Consultants, and she continues her work in Open Innovation through her role as a Visiting Industrial Fellow at IfM, Cambridge University.

Dr Tim Minshall is a Senior Lecturer in Technology Management at the Centre for Technology Management at the Institute of Manufacturing, University of Cambridge (UK). His research interests include technology enterprise, funding of technology enterprises, university technology transfer and open innovation. He is a member of the Board of St John's Innovation Centre. Before joining the Centre, he was a Project Manager and Board Member at St John's Innovation Centre Ltd where he worked on a series of projects to support industry / academic collaboration focused around new technology ventures. Prior to working at St John's Innovation Centre, he worked as a teacher, consultant, plant engineer and freelance writer in the UK, Australia and Japan. Tim has B.Eng. from Aston University and a PhD from Cambridge University Engineering Department. 


\section{INTRODUCTION}

It is nowadays commonly acknowledged that innovation is at the source of competitive advantage for companies. In order to innovate, companies need to have an efficient management of their internal resources as well as their external relationships. They need to manage increasing specialisation while at the same time exploring new opportunities for innovation. Current times have often been referred to as characterised by a knowledge-based economy and fast pace technological change. In this difficult environment, companies compete to maintain a relevant position.

Current studies on technology management have emphasised the importance of keeping abreast with technological development by adopting technology intelligence (TI) strategies - i.e. by establishing activities for the systematic capture and delivery of technological information to decision makers that can help an organisation to be better aware of technology threats and opportunities (Kerr, Mortara et al. 2006) .Kerr et al. (2006) developed a conceptual model to operationalise TI activities.

$\mathrm{TI}$ is typically operationalised by setting up a number of activities, employing people with specific skills and profiles and by implementing infrastructural support (Mortara, Kerr et al. 2009). Among these activities, a number of companies have chosen to establish 'listening posts' (Gassmann and Gaso 2004; Gassmann and Gaso 2005) in areas of intense innovative activities, for example, in regional clusters. According to mainstream thinking, by being in a particular location companies can better access knowledge, in the more tacit form, through participation in the local 'buzz' accessing first hand the up-to-date news in the region. In fact, within regional clusters technical information flows are known to be particularly intensive. The easy flow of knowledge, the transfer of ideas is argued to contribute to greater dynamics of knowledge creation and exploitation. By operating within a cluster, companies can thus have an easier access to knowledge. Moreover, vertical interactions along the value chain, horizontal interactions between competing companies and exchange between suppliers and consumers enable the companies "participating" in a cluster to capture the regional market trends and preferences and help them to take a decision concerning their future technological focus and to identify the frontiers and the limits of their knowledge. The advantages of clustering have been abundantly argued theoretically as well as empirically to show how it can support innovation through the capture of information and knowledge. Similarly, researchers have made lots of efforts to develop applied models for TI strategy. Yet, we know very little about how these two processes of knowledge capture are linked. Companies cannot afford to setup a technology outpost in every single geographic area where innovation and technological development are intense and relevant. Hence, companies need to develop a TI strategy for reaching out and explore remotely what science and technology is being developed across, potentially, long geographic distances by throwing out global pipelines (Bathelet, Malmberg et al. 2004). A question remains to understand how the existence of clusters and of local knowledge interface organisations could facilitate the access of knowledge for firms external to the cluster.

Therefore analysing the interplay between $\mathrm{TI}$ activities and the features of clusters is promising for understanding the mechanisms by which the efficiency of TI strategy could be improved by being 
embedded in a cluster. The objective is therefore to look at how do companies organise and implement TI activities to leverage on the knowledge and existence of regional clusters? Particularly concerning the first step of the strategy, i.e. the capture of relevant new technological information.

To answer this question this chapter will first present and define Technology Intelligence. In the second part, the features of regional clusters are reviewed and we discuss how they can be particularly relevant in addressing TI needs. In the last part we examine, a particular case study of how Kodak accessed both the local knowledge by being embedded in a high tech cluster and developed a TI strategy to allow them to access knowledge from other locations.

\section{TECHNOLOGY INTELLIGENCE: AN IMPORTANT ACTIVITY FOR THE INNOVATION STRATEGY}

Maintaining and increasing the pace of innovation is a fundamental requirement for companies in today's evolving markets. In order to achieve this goal many companies are embracing a new innovation approach, which relies on inputs coming from outside the company's boundaries. This approach has been framed by academics as 'open innovation' (OI) (Chesbrough 2003). It implies that companies' boundaries become more 'permeable' to allow the identification and exploitation of opportunities from the external environment. Innovation is becoming an increasingly distributed process involving players dispersed across the globe, open to innovate through possible different value chain configurations (Fraser, Minshall et al. 2005). Identifying potential innovation partners, recognising opportunities and threats, is an important step in the 'open innovation' process. In fact, in the most recognised OI process (Want $\rightarrow$ Find $\rightarrow$ Get $\rightarrow$ Manage; (Witzeman, Slowinski et al. 2006)), 'Find' implies identifying opportunities (and threats) coming from the external environment.

Knowledge about new technologies can offer firms a competitive edge if it is paired with knowledge regarding market opportunities and competitor's domains (Deschamps and Nayak 1995). Consequently, companies set up intelligence activities dedicated to keeping abreast of interesting and relevant developments in the environment. With a specific focus on technological information, technology intelligence ( $\mathrm{TI}$ ) activities concentrate on capturing and delivering technological information as part of the process to develop an awareness of technology threats and opportunities (Kerr et al., 2006). The $\mathrm{TI}$ activity is not only about simple knowledge management and information processing: its purpose is to provide 'intelligence consumers' (i.e., decision makers) (Bernhardt 1993) with analysed, contextualised and purposeful intelligence. Recent academic research has been directed to explore this particular activity and has resulted in several works in this area (Savioz and Blum 2002; Lichtenthaler 2003; Gassmann and Gaso 2004; Lichtenthaler 2004; Lichtenthaler 2004; Savioz and Tschirky 2004; Gassmann and Gaso 2005; Lichtenthaler 2005; Lichtenthaler 2006; Savioz 2006; Lichtenthaler 2007 ; Arman and Foden 2010; Rohrbeck 2010).

For most practitioners, technology intelligence is a required resource. However, in many cases current technology intelligence activities are not structured and organised. Mortara et al (2009) studied 14 UK technology-based companies in a variety of sectors looking at the different approaches the companies were using to gather information, exploring their strengths and weaknesses and identifying practical ways to address common problems. 
They also developed a model (Kerr et al., 2006), which can help companies in structuring their TI activities. The model comprises four principal search modes (Fig. 1) for gathering information.

The internal modes look for information inside the organisation:

- Mining: extracting explicit intelligence information from internal resources such as libraries and databases.

- Trawling: making in-house information explicit, particularly information that is not known to be there.

The external modes are used to capture new relevant information:

- Targeting: focusing on identified relevant new technologies outside the company and monitoring their development.

- Scanning: keeping abreast of any unforeseen developments that could have an impact on the business.

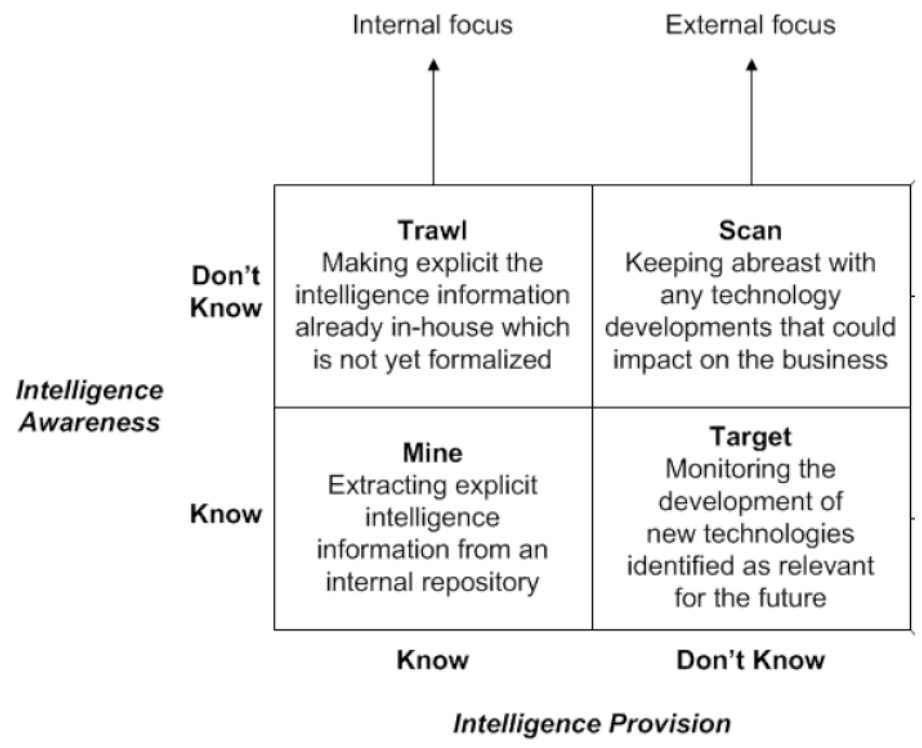

Fig. 1: Tl search modes (Kerr et al., 2006)

Through cross comparison of company case studies (Mortara, Kerr et al. 2009) and building on Kerr et al.'s (2006) theoretical model, a generalised set of elements (toolbox) which can be used to map and characterise a TI system was proposed. This work highlighted that social network connections have a dominant role in any intelligence system. An initial model (Fig. 2, (Mortara, Kerr et al. 2009)) was developed combining Stephenson's (1999) model of social networks with the observation of practice. The model suggests that a company establishes links with primary sources of information via the external gatekeepers (the scouts), while Scan provides the connection with a large number of non pre-identified sources of information across the environment. Both target and scan could be operated through links with primary or secondary sources of information. The importance of links with secondary sources (intermediaries who can pass information between two groups) can be seen in the example shown in Fig. 2: where, by connecting to three intermediaries, the company achieves secondary connections with eight primary sources of information. However, social networks with intermediary 1 and 2 are clustered (Uzzi and Dunlap 2005) as they both reach start-up A. Making the connection with intermediary 1 is somewhat redundant. On the other hand, intermediary 4 allows 
the connection to the network of intermediary 3, giving access to 5 information sources through secondary contacts.

Researchers working in the field of social networks have long since highlighted the importance of weak ties (Granovetter 1983) i.e. the relationships that enable the connection between different social groups, to reach the most useful and relevant information. Networks enable information flows deriving from the social linkages that connect employees from different companies (Almeida and Kogut, 1999). Social exchanges therefore require physical proximity and regular interactions. This is the reason why scholars working in the field of economic geography and economic sociology show that there is a significant qualitative difference between local and global networks (Witthington et al, 2009). Therefore, it would be interesting to examine what features of localised innovation networks or regional clusters- technology intelligence systems can leverage.

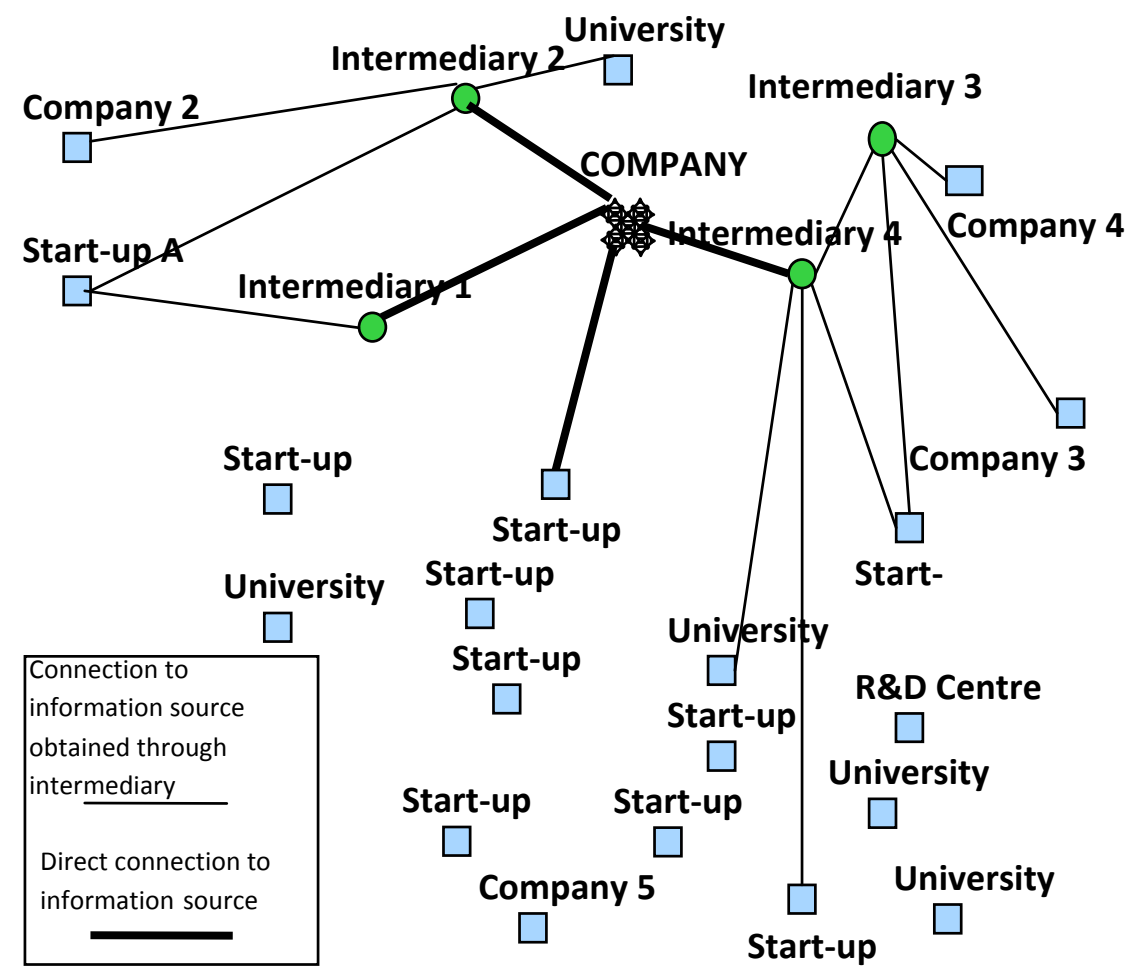

Fig. 2: Representation of TI external networks. An example observed during past research. (Mortara et al, 2009)

\section{Regional CLUSTERS AND INNOVATION}

\section{The innovation capabilities of clusters in the context of open innovation}

Regional clusters have triggered a huge strand of literature. Amongst the studies, the attention of the scholars has increasingly been focused on the analysis of how clusters' networks can support innovation. This is due to the fact that innovation is nowadays seen as a collective process, which 
involves many different actors that need to combine their resources for innovation. Whilst traditionally companies have operated a 'closed innovation' model where they rely only on internal $R \& D$, companies now adopt an open approach to innovation by allowing external access to their innovation processes and reaching out to external knowledge. In fact, increasingly firms are getting involved in collaborations that transcend sectors and country boundaries. In this perspective, participating in, and accessing regional clusters is particularly relevant. Regional clusters can enhance the capacity for innovation (Maskell, 2001) as they promote the exchange of information and the combination of complementary knowledge (Von Hippel 1988, Lundvall 1992) through local social interactions (Garnsey and Longhi, 2004). However, the front-end process of innovation is particularly tricky for companies as they need to capture the most recent and relevant information. This information is usually tacit and therefore highly dependent on its social context and it is known to be "sticky context-laden" (Asheim, Gertler 2005). Tacit information is often bound to a geographic location and requires contextual understanding. Spatial proximity enables people interactions that favour the exchange of tacit knowledge thanks to physical encounters, informal and face-to-face exchanges that enhance trust and a fast diffusion of new ideas. These dynamics are often referred to as "localised knowledge spillovers". Companies search for a constant renewal of their knowledge through the exchange and capture of informal knowledge that would accelerate their technological advancement (Audretsch, Feldman 1996; Garnsey, Longhi 1998). Interacting within clusters facilitates this complex process.

\section{How firms gain by interacting in clusters?}

The transfer of information and knowledge that can assist innovativeness can proceed through several dimensions within a cluster: the structural dimension, the relational dimension and the cognitive dimension (Dang, Thomas and Longhi, 2010). Among the three dimensions, the capture of relevant information is particularly concerned with the structural and the relational dimensions.

\section{The structural features of clusters}

Significant research exists on the structural features of regional clusters. Previous work mainly focuses on the way actors can benefit from localised knowledge spillovers (Audretsch and Feldman, 1996; Breschi and Lissoni, 2001) depending on the structure of interactions in clusters networks. Regional advantages derive from the existence of dense networks of interaction between actors but the benefits vary according to several mechanisms.

\section{Type of links and position in the network}

It is suggested that the analysis of the actors' position in the network and the type of links have an impact on the way they can access relevant information for innovation (Burt, 1992). The importance of the structural dimension is also pointed out by Kogut (2000) who argues that, in a technology cluster, the network of relationships between participants is the principal source of knowledge and this is related to the networking potential (Saxenian, 1994; Sorenson et al, 2006). Capaldo (2007) 
outlines the nature of "dual networks" on innovative capabilities. Dual networks refer to structure of networks in which a small core of strong ties is integrated in a larger periphery of weaker ties. Weak ties speed up innovation by expanding the network diversity, whilst strong ties stimulate knowledge transfer (Granovetter, 1985). However, as ties and connections are typically constrained by distance, the geographical concentration plays a crucial role. The integration of a company in a cluster enables them to mobilise both strong ties as well as weak ties. The potential benefit of networks regarding the capture of new information is therefore enhanced when companies embed themselves within a cluster. Besides, Owen-Smith and Powell (2004) claim that the innovative capabilities of networks also depend on the position of actors within the network. Powell, Koput, and Smith-Doerr (1996) show the importance of being central to the network, centrality being measured by the number and importance of strategic alliances between organisations. As shown by recent studies (Giuliani and Bell, 2004) information and knowledge flows in cluster networks are not diffused evenly 'in the air' as stated by Marshall (1920): some companies may be isolated from relevant information if they are not central to the network. Also the number of connections between actors could be used as a measure of centrality in the network (Uzzi, 1996).

\section{The local global trade-off}

For a firm, being embedded in the cluster, or at least having an outpost which acts as an interface between the main firm headquarters and the local actors and networks, is crucial. This is also highlighted in the works on gatekeepers of knowledge, (Allen, 1977, Lazaric et al, 2008, Rychen, Zimmermann, 2006) where the role of the gatekeepers is to create links and channels both inside and outside the cluster. As suggested by Wilkinson et al. (1998), successful clusters are those, which combine dense internal inter-firm interactions but also synergies with external, and often global, networks. Current research also shows that cluster performance does not only result from the quality of interactions and coordination inside the cluster but also from external networks and cooperation with distant rivals or partners (Rychen and Zimmermann, 2006). One main advantage of clusters is based on their capacity to foster complementarity between dense internal interactions that sustain innovation and at the same time fulfil the needs for external and global knowledge. Most clusters have "technological gatekeepers" (Allen 1977), actors that "link their organisation to the technological world at large". This concept refers to the problem of communication in technology in the context of R\&D organisations. As stated by Rychen and Zimmermann (2006), indirect flows of information are forwarded through opinions leaders. These gatekeepers are the people or organisations that "for various reasons, tend to become more acquainted with information sources outside their immediate community. They either read more extensively than most or develop personal contacts with outsiders. A large proportion of these people in turn attract colleagues from within the community who turn to them for information and advice" (Allen, 1977, p.150, quoted by Rychen et al 2006). Technological gatekeepers are interfaces between internal and external resources enabling local actors to take advantage of their own external relations but also give external actors access to local resources. They also play a role in internal co-ordination as they are very well positioned to know what expertise and local skills they should mobilise and combine to draw benefits from geographical proximity effects. 


\section{The social and relational features of clusters}

The influence of geographical proximity is beneficial only when strategic alliances link local actors (Almeida and Kogut, 1999). The access to new knowledge is not only the result of interactions between actors, but the type of relations, whether formal or informal, business alliances, commercial relationships or social interaction between actors do play a role.

\section{Clusters as a combination of vertical and horizontal relationships}

If the cluster combines competitors' competencies as well as partners' competencies within the same industry, innovation is stimulated by competitive action.

Porter (1998) has identified that interactions between competitors and collaborators in a cluster is a crucial element of cluster innovation dynamics. The 'horizontal relationships' - i.e. those with competitors - create a lot of pressure on firms who are anxious to emerge well in any comparisons. Horizontal interactions with competitors give companies close cognitive repertories stimulating observation, comparison and exchange of information that create a local buzz resulting in a perpetual updating of information. In this perspective, clusters can be viewed as ideal incubators for innovation (Preissl, Solimene 2003). They foster relationships and regular interactions that create and support new markets. This dynamic creates a definitive push towards innovation.

Also 'vertical relationships' - i.e., relationships along the supply chain - also stimulate innovation within clusters. Malmberg and Maskell (2005) refer to this as "learning by interacting". They claim that vertical interactions in clusters with 'sophisticated' consumers enable companies to formalise and anticipate their offer and update their knowledge about the market.

\section{Embedding actors within a cluster and the effects of "Local Buzz"}

Local interactions are based on social relations that are due to, and fostered, by co-location. The cluster structure of embedded actors relies on the interdepencies between these individuals, which have evolved over time (He, 2006; Bathelt, 2008). In fact, as claimed by Storper and Venables (2003), the local buzz is a privileged channel for knowledge flow, particularly when the knowledge is tacit. Companies benefit from being embedded in a cluster bacause their employees regularly interacting with other actors allowing for the exchange of tacit knowledge. While codified knowledge can be quite easily diffused with any communication means, informal and tacit knowledge is spread rather accidentally. Neither the transmitter nor the receiver knows in advance about its relevance before it is communicated (Saxenian 1994, Feldman 1994). This exchange of informal new knowledge accelerates technological advancement. This local buzz is the key difference between local and global networks (Witthington et al, 2009). Indeed, the concept of local buzz developed by Storper and Venables (2004) refers to "the information and communication ecology created by numerous faceto-face interactions (...)" (Malmberg and Maskell, 2006). According to these authors, this buzz consists of information continuously exchanged and updated both through intended and unanticipated learning processes, for example in organised and accidental meetings. The buzz exists because of a number of tacit constructs such as the application of the same interpretative frameworks and a shared understanding of new knowledge and technologies, as well as cultural traditions and habits. These conditions, typical of a cluster, make interacting and learning less costly. 
Personal contacts are hence considered a necessary element in the transfer of knowledge and it implies that a certain degree of cognitive proximity exists through which people can achieve a mutual understanding of new technologies. Cooke (2006) has pointed out that clusters accumulate knowledge and in time become a rich knowledge base, which he refers to as "leading knowledge". Firms are attracted by this 'leading knowledge' and may decide to establish themselves in the cluster in order to capture knowledge spillovers (Hervas-Oliver and Albors-Garrigos 2008).

In summary, regional clusters constitute an important lever for Technical Intelligence strategy. They allow vertical interactions along the value chain and horizontal interactions between competing companies. The exchange between suppliers and consumers enable firms to understand and capture the regional market trends and preferences and help them to take a decision concerning their future technological focus and their next investments. Besides, direct interaction with a cluster is widely recognised to be a necessary condition for establishing trusting relations and communicating sensitive, early-stage knowledge and information. Technical information flows are particularly intensive and facilitated in clusters thanks to the "local buzz" or, in other words, the networking potential. Finally, clusters' global pipelines represent privileged channels and conduits for information flows between local companies and external networks enhancing a fast diffusion of new ideas. Clusters represent a significant mean for the establishment of trans-local relations in common situations of incomplete knowledge and uncertainty. 'Local buzz' and global pipelines are thus, mutually reinforcing mechanisms (Bathelt et al. 2004) helping companies to identify the frontiers and the limits of their knowledge, and to capture new technical knowledge.

The following section will explore how these theoretical concepts and cluster characteristics are reflected in the TI strategy developed by Kodak. We will focus on how they accessed the local knowledge by being embedded in a high tech cluster (Cambridge, UK) and how they developed global pipelines to access knowledge in other locations.

\section{Development of a ti strategy at Kodak European Research: accessing knOWledge through INNOVATION CLUSTERS}

Kodak is a US-based multinational company employing over 20 thousand people globally. It currently has a local presence in more than 50 countries worldwide. This global presence has been established since the company's foundation in 1888.

The current Kodak business focuses on three major areas - Consumer Digital Imaging, Graphic Communications and Film, Photofinishing \& Entertainment. Kodak offers products and services for a broad range of imaging applications for consumer, commercial and industrial customers. The innovation commitment of Kodak is demonstrated by their extensive patent portfolio and by their strong and respected brand.

Following the growth of digital technology and Kodak's diversification into a wide range of imaging/printing technology businesses it was clear that for future innovation internal resources alone were not sufficient. Kodak hence adopted an Open Innovation strategy to complement internal innovation initiatives and, as part of this; in January 2006 they established an 'Open Innovation' 
centre (Kodak European Research (KER)) in Europe. KER had the mission to identify opportunities and partners of strategic importance within the European, African, and Middle Eastern Region (EAMER) (Mortara, Thomson et al. 2010).

Although KER was closed in 2009 due to the 2007-2008 financial crisis, the story of how KER's TI strategy was developed represents an interesting case study to understand how $\mathrm{TI}$ and the communication strategy of a company can be influenced by the existence and activity of knowledge clusters. In particular, the following sections will discuss 1 ) how KER benefited from the Cambridge location and 2) how KER could leverage other regional clusters around Europe by connecting through "global pipelines" (Bathelet, Malmberg et al. 2004). In particular, this case study will discuss the communication approaches adopted at KER to carry out their scouting activity and how these approaches were refined through the experience of 3 years of activity.

\section{The Cambridge knowledge cluster}

Cambridge, UK, was chosen by Kodak as the base for KER from which to begin the exploration of the whole of EAMER. Cambridge is characterised by a high density of "actors and networks" (Cooke and Huggins 2003) and by extremely efficient informal channels and personal relationships which have developed since the origin of the cluster. The primary specialisation fields of the cluster are ICT and life science, especially biotechnologies (Huggins 2008) as well as ink jet printing (Drofiak and Garnsey, 2009). Of particular importance for the cluster is the role of the University of Cambridge and its spinoff companies (Garnsey and Longhi 2004). The university plays a key role in the development of new technologies, in the foundation of new spin-off firms, in the creation of inter-company networks and generating a highly qualified workforce (Garnsey and Heffernan 2005). In addition to the university, the cluster encompasses a number of key players including intermediaries and consultancy organisations such as Cambridge Consultants and TTP as well as a rich Venture Capital community. Cambridge has several sites dedicated to innovation, including science parks and incubators. Thanks to the interplay between all these organisations, Cambridge has seen real success stories. One of the most famous is that of ARM (originated as the joint venture between Acorn and Apple and with the support of serial entrepreneur Herman Hauser). ARM is now the global leader in the licensing of microprocessors and chips. Also CSR is a success example, a global company in the ICT sector originally spun out from Cambridge Consultants. Cambridge's dynamic environment has attracted multinational corporations from a diverse range of sectors including Microsoft, Hitachi, Toshiba, Rolls Royce, Schlumberger, Philips, Nokia, GSK and Unilever. They have come to Cambridge to benefit from the 'local buzz'. Some of these companies have partnered with the University to fund University-Industry research initiatives and establish R\&D centres. In addition, Cambridge Network Ltd. is a local organisation that focuses on reinforcing and expanding the ties across the network by acting as a knowledge intermediary. Of particular success are events such as the 'Corporate Gateway', an event-showroom where external companies are introduced to ideas and technology from Cambridge and the East of England region through bespoke visits and seminars. 


\section{Accessing the 'local buzz'}

The Cambridge cluster was chosen as the primary location and base for KER's activity. A number of factors impacted on this choice, including the relevance of the technical knowledge in the cluster to Kodak's business, the strength of the start-up and venture capital communities but also including the softer aspects of the lifestyle of the region, the communication and transport channels, and the opportunities for identifying and recruiting competences in the area. According to Kodak's managers involved, the ability of the local investment agencies and cluster organisations to 'sell' Cambridge as an attractive and unique location helped determine this as the location for KER. The agencies portrayed a clear image of how the cluster differs from others, the core skills and capabilities that are accessible, as well as the benefits and opportunities of participating in local initiatives. Through initiatives such as the Corporate Gateway organised by the Cambridge Network, Kodak could appreciate the specialicisms of the area and make the first business connections even before setting up their own establishment.

Once KER was established, in order to access local knowledge, the 25 KER staff developed an active programme of participation in Cambridge activities, events, networks workshops and interest groups. Actively participating, for example by speaking at local events, was key:

"It was important for us to start disseminating our message, telling people directly about the 'Open Innovation' strategy at Kodak and about the new and exciting venture of the KER centre. You want people to hear the story from you so that the message is clear. New comers to clusters, particularly those with big brand names, always attract a lot of interest and if the message is not clear, coherent and directed, it is inevitable that contrasting voices will emerge. By spreading a consistent message and by being 'open' about what we wanted to achieve we could really make the most of the 'initial splash' of moving to Cambridge. Our experience of moving to the Cambridge cluster was that many people came forward to introduce us to different groups and to help us make the most of the cluster networks. Actively participating in the networks is important not only because you want your company to be known, but also you want to be known personally as a representative of the company. "- Ruth Thomson, Innovation Leader at KER

Particular attention was paid to the PR messages about why Kodak moved to Cambridge and what they wanted to achieve at KER. In these messages it was explained what technologies and fields were of interest, the ways in which Kodak could collaborate with different partners and who at Kodak should be contacted to begin a discussion. This allowed the community to immediately identify the gatekeepers at Kodak and the best ways to communicate and propose ideas and technology. Ruth Thomson also noted that having a strong initial PR message has the side effect of raising expectations in the community and people might use the message to evaluate progress and results before these can be realistically achieved and/or communicated externally.

Being in the cluster had many advantages due to the predicted availability and access to local technology and networks. The plethora of relevant events 'on the doorstep' made it possible to 
easily attend events just for part of the day or in the evening, making the best of the internal resources.

"The flip side of this is that there is so much always going on [locally] that it was very difficult not to be totally absorbed by the local events with the risk of spending the majority of time in Cambridge and neglecting opportunities in the rest of the EAMER!" - Ruth Thomson

\section{Establishing global pipelines}

To reach out the rest of the EAMER, KER developed a four-step TI strategy based on the TI model (Kerr, Mortara et al. 2006) in Fig. 1. The process is shown in Fig. 2 (Mortara, Thomson et al. 2010) and progresses from an open search for information on what interesting technology, knowledge and clusters exist in different countries in the EAMER (Scan (Kerr, Mortara et al. 2006)) to the targeting of relevant technological areas through the establishment of links and relationships with key contacts and groups across EAMER.

The first step consisted of the understanding of the context and background of the regions across EAMER and in particular, how science, technology and innovation are developed and supported in those regions. This step was achieved through a systematic desk-based creation of background "country guides". These were living documents collating key information relative to the different regions. These guides formed the background knowledge for both the identification of the regions to be explored and of relevant organisations that could act as knowledge intermediaries to facilitate access to the area. For the development of the guides a clear set of rules were established (see Mortara, Thomson et al. 2010).

Intermediaries of knowledge, i.e. people and organisation that could provide support in accessing local knowledge, especially in areas of dense science and technological development such as clusters, helped KER to establish a visit itinerary.

"Working with intermediaries made the task of accessing technology and clusters significantly more efficient. Intermediaries understand their own region so they can help you understand the context of the innovation environment. Working closely with them and helping them to understand your interests and objectives means you can identify the real opportunities. In this way you can make the most of a potential visit and follow-up interactions, while building an ongoing relationship with key contacts in the region" - Ruth Thomson

Intermediaries ranged from local and national development agencies, to Venture Capitals and consultancy organisations. In some cases, single individuals provided feedback and access to local knowledge. Some intermediaries were privately owned, others were part of universities, science parks, or public bodies at a local national or international level. 
Looking for relevant technologies across the region

Scan Target

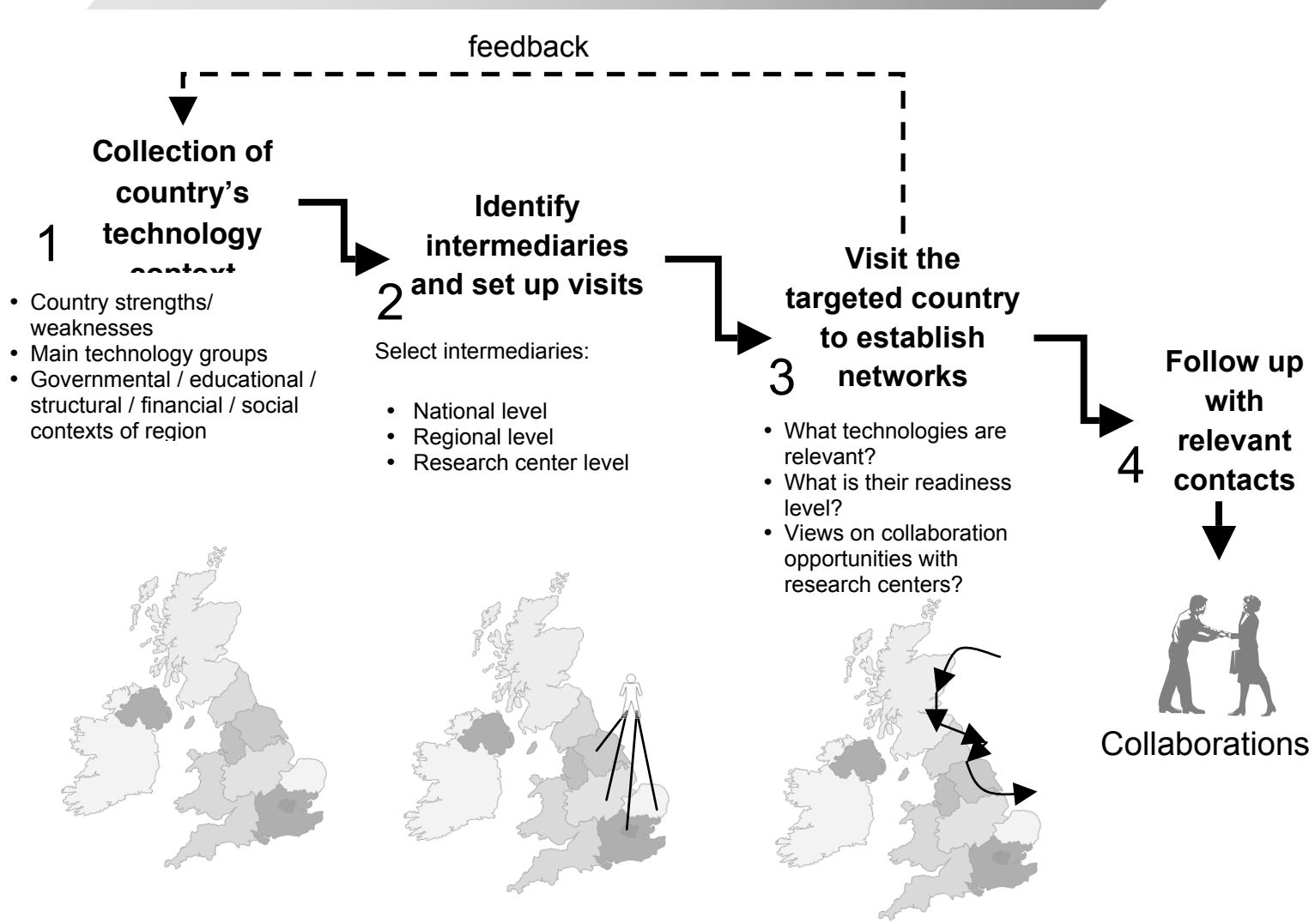

Figure 3. Technology intelligence at KER, moving from Scan to Target (Mortara, Thomson et al. 2010).

"There was a great difference between the [intermediary] options and the response we got from them. Some told us too much, without tailoring the information to our needs, others too little so that we were unable to evaluate the advantages we would have had in collaborating with them and in visiting the region." - Ruth Thomson

Problems in the identification and evaluation of intermediaries often came because they did not explicitly explain the unique differentiation of their activities and their region; they did not explain their focus and specialities. There can be many organisations proposing themselves as the intermediary of choice for the same area and for those external to the local context it can be quite difficult to determine who they should collaborate with. It could be much easier to appreciate how a cluster or a region differentiates itself if there is a clear reference to the specificity of cluster knowledge (for example, when it is reflected in the name of the intermediary organisation or clearly stated on the website). However, the downside to this is that there is the risk that by forcing labels and over generalising the knowledge of the cluster, one could overlook interesting opportunities.

KER developed a triangulation approach and a clear checklist to assess information from intermediaries (Mortara, Thomson et al., 2010) reported in Fig. 5. 


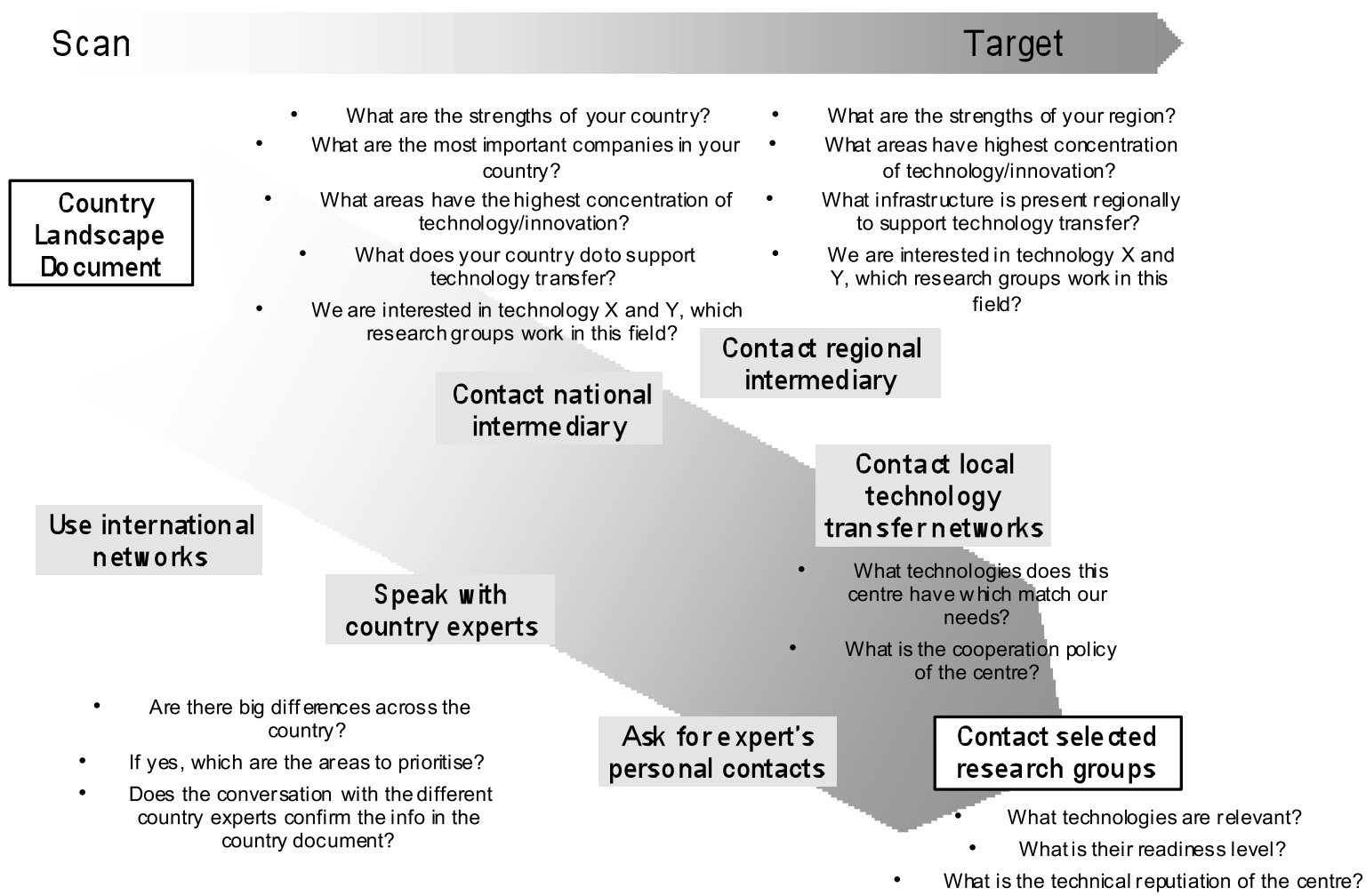

Figure 4. In order to gain the most objective understanding and identify the best contacts for KER in a certain region, KER reviewed and compared information gathered from different intermediaries. This approach helped to reduce the potential bias of any single intermediary and to capture a larger set of information.

Equally, it was very important to be coherent and clear about what Kodak wanted from the visit and the opportunities for potential collaboration. Talking with the intermediaries prior to the visit, iterating ideas for the itinerary and being clear what KER wanted out of the visit was key.

Once arranged, visits to the designated region took place. The communication strategy was carefully planned in order to maintain a coherent and open discourse with the contacts.

"It was very important that we were 'open' too. We knew that contacts would be doing their 'due diligence' on us, both as KER, and us as individuals - we would be 'Googled'! We wanted to make sure that they found accurate and 'open' information that would help facilitate interaction." - Ruth Thomson

A brochure and a presentation with important information were prepared to be circulated as widely as possible where KER explained its needs and interests and routes to collaboration.

"Due to our strong brand equity and the association of the 'Kodak' name with photography it would be easy for people to assume that we wouldn't be interested in anything else. However our interests were diverse across the wide range of current and future printing and imaging technologies. It was important we communicated this clearly." - Ruth Thomson 
A double-act approach to the scouting visits was adopted whereby KER sent teams with a balance between technical expertise and commercial understanding. This helped the dynamics during the visits and the dialogue between the scouts and their hosts.

Once back from the journey, KER scouts followed up on connections and potential collaborations. Obviously, the visits did not always lead to immediate collaboration, however, as part of the TI strategy, KER provided feedback and follow up.

"We understood the value of the connections and networks we had established as part of a visit. Even if something was not of interest at present it might have been in the future. Intermediaries in particular are an exceptionally important conduit of knowledge and could be the key to the discovery of future opportunities. Providing feedback to them about what was/was not of interest significantly improving their knowledge on what we might could be of interest in the future and by maintaining these connections we built up an effective network across EAMER." - Ruth Thomson

\section{DISCUSSION- CONCLUSION}

Technology intelligence is an important firm activity to keep abreast with technological developments. One means of enhancing a firm's ability to perform $\mathrm{Tl}$ effectively is to establish "listening posts" in areas of intense innovative activity, such as regional clusters. However, companies cannot afford to setup technology outposts in every single area of potential interest. This paper discussed an example of how companies can develop a TI strategy that enables them to explore remotely science and technology developments across long geographic distances. This chapter discussed also an example of how a company benefited from being embedded within a regional cluster, and how they could also set up strategies to enable them to access knowledge from other remote regional clusters.

This case study illustrates this through the example of Kodak European Research, and examines the role of regional cluster networks' main features in facilitating Kodak's TI strategy. Kodak TI strategy benefited from Cambridge clusters' local and global networks in two ways. On the one hand, Kodak has built connections within the cluster taking advantage of it's position in Cambridge. Also the case study has highlighted how Kodak could access knowledge in other clusters by linking to intermediaries such as development agencies, university Technology Transfer Offices etc around EAMER.

By interacting with the Cambridge cluster, Kodak became more central to the local network as it could directly access relevant local knowledge that was not easily reachable from the headquarters in America. The literature refers to centrality as the number of strategic connections a company gains by interacting in the cluster. Through KER, Kodak accessed a great number of relevant local networking events such as those facilitated by Cambridge Network Ltd and could start numerous relationships with local actors. However, although literature suggests the 'number' of connections as a potential metric for the centrality of the network, practice at Kodak suggested that the 'number' of connections is a somewhat irrelevant metric for the scouts. First of all, Ruth Thomson points out: "what is valuable about connections is not their number but their relevance and pro-activeness. Besides, it is not enough to talk with people once and count them as a 'connection', connections need 
to be fostered and maintained". It is not the number of connections that is beneficial, but rather the quality, relevance and 'freshness' of the connections. This suggests that there is the need for more dynamic and qualitative metrics of networks. Additionally, if one still desired to measure the number of connections one should also keep track of the connections that could be accessed through each relation. Although in current times people networks are becoming more explicit through systems like linkedIn ${ }^{\circledR}$, this approach to measuring relationships somewhat misses the point of the value of personal connections and the importance of the trust that can be established between individuals. Furthermore, the number of connections can be only interesting as a relative measure for a scouting activity, i.e., if the total possible number of connections is known or if one could directly compare how many connections others scouts in the outpost have gained. But the number of possible connections will be constantly changing and therefore very difficult to capture.

Through its presence in the Cambridge cluster KER became the intermediary between the cluster and Kodak's headquarters. Through KER, Kodak could more easily capture local knowledge from EAMER, and bring information to their headquarters that was external to the cluster. Thus, KER constituted a global pipeline and conduit for information flows between local companies and Kodak headquarters, enhancing the fast diffusion of new ideas. Fig. 5 shows the two types of channels.

The Cambridge cluster combines dense internal inter-firm interactions but also synergies with external, and often global, networks. The clusters constituted a significant channel for the establishment of trans-local relations. To reach these external connections KER benefited from the help of several organisations who acted as gatekeepers for their local knowledge. KER emphasised the importance of these intermediaries and considered them as an integral part of their social network (Mortara et al 2010b). The role of intermediaries was fundamental both within Cambridge (e.g. "Cambridge Networks") and outside Cambridge. These agencies played the role of interface between internal actors and external new actors, giving Kodak access to the extremely efficient local informal relations and with it, the news and tacit information in the region: the "local buzz". This suggests that further research within the field of $\mathrm{TI}$ and regional cluster should be directed to understand how companies could identify and select the best intermediary configuration.

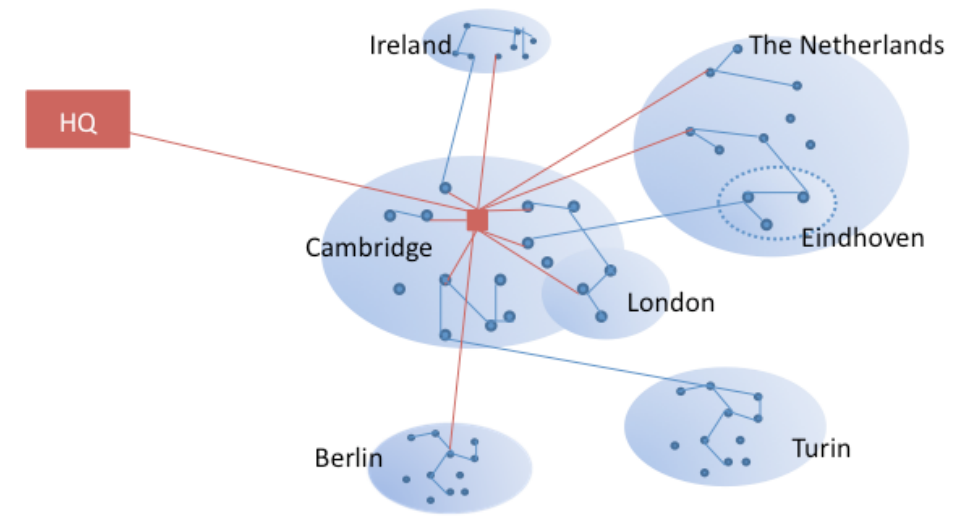

Figure 5: A visual representation of Kodak's networks. Although this is by no means an exhaustive description of the networks established, this picture qualitatively indicates the diverse types of networks across different regional clusters accessed by Kodak through KER 
Overall, the research bridges the gap between two domains of research, whose integration can give insights into the mechanisms by which $\mathrm{Tl}$ activity of capturing knowledge can be enhanced by location. In this perspective, this paper has explored the value of (1) being embedded within a cluster, and (2) remotely accessing the knowledge of a cluster, and how these two approaches can be combined to support a company's TI strategy.

\section{References}

Almeida P., Kogut B. (1999), Localization of knowledge and the mobility of engineers in regional networks. Management Science, vol. 45, $n^{\circ} 7$

Allen T. J. (1977) Managing the Flow of Technology: Technology Transfer and the Dissemination of Technological Information Within the R\&D Organization. MIT Press, Cambridge

Arman, H. and J. Foden (2010). "Combining methods in the technology intelligence process: application in an aerospace manufacturing firm." R \& D Management 40(2): 181-194.

Asheim, B. T. and Gertler, M. (2005), The Geography of Innovation: Regional Innovation Systems in: Fagerberg, J., D. Mowery and R. Nelson (eds.), The Oxford Handbook of Innovation. Oxford University Press

Audretsch, D.B; Feldman, M.P. (1996), R\&D spillovers and the geography of innovation and production, The American Economic Review; Vol. 86, N³

Bathelet, H., A. Malmberg, et al. (2004). "Clusters and Knowledge: local buzz, global pipelines and the process of knowledge creation." Progress in Human Geography 28(1): 31-56.

Bathelt H. (2008), Knowledge-based Clusters: Regional Multiplier Models and the Role of 'Buzz' and 'Pipelines'. in Karlsson, C., Handbook Of Research On Cluster Theory, Edward Elgar, 336 pages.

Bernhardt, D. (1993). Perfectly legal competitor Intelligence, Pitman Publishing.

Breschi, S., Lissoni F. (2001), Localised knowledge spillovers vs. innovative milieux: Knowledge "tacitness" reconsidered. Papers in Regional Science, Vol.80

Burt R. S. (1992), Structural Holes. The Social Structure of Competition, Cambridge, Harvard University Press

Camagni R., Capello R. (2000), The Role of Inter-SME Networking and Links in Innovative HighTechnology Milieux, Chapter 5 in Keeble, D. and Wilkinson, F. et al., 2000.

Capaldo A. (2007). Network structure and innovation: The leveraging of a dual network as a distinctive relational capability. Strategic Management Journal, vol. 28 
Carbonara N., (2004), Innovation processes within geographical clusters: a cognitive approach, Technovation, vol. 24.

Castell, M., Hall P. (1994), Technopoles of the World. London: Routledge

Chesbrough H. (2003), Open Innovation: The New Imperative for Creating and Profiting from Technology. Boston: Harvard Business School Press.

Cooke, P. (2006), Global bioregional networks: a new economic geography of bioscientific knowledge. European Planning Studies, vol.14

Cooke, P. and R. Huggins (2003). High-technology clustering in Cambridge (UK). The institutions of local development. F. Sforzi. Aldershot, UK, Ashgate: 51-74.

Dang R. J., Thomas C., Longhi C. (2010), What can help small firms accessing knowledge in territorial innovation networks?. 26th EGOS Colloquium, Lisbon, Portugal. 2-4 July 2010

Deschamps, J. P. and P. R. Nayak (1995), Product Juggernauts: How Companies Mobilize to Generate a Stream of Market Winners. Boston, HBS Press.

Drofiak A, Garnsey E. (2009), The Cambridge High Tech Cluster: resilience and response to cyclical trends, CTM working papers.

Fraser, P., T. H. W. Minshall, et al. (2005). The distributed innovation pradigm: Evolution and dynamics. 6th International CINet Conference Continuous Innovation -(Ways of) making things happen. Brighton, UK.

Garnsey, E. and C. Longhi (2004). "High technology locations and globalisation: Converse paths, common processes." International Journal of Technology Management \& Innovation 28()(3): 336355.

Garnsey, E. and P. Heffernan (2005). "High-technology clustering through spin-out and attraction: The Cambridge case. ." Regional Studies 39(8): 1127-1144.

Gassmann, O. and B. Gaso (2004). "Insourcing Creativity with Listening Posts in Decentralised Firms." Creativity \& Innovation Management 13(1): 3-14.

Gassmann, O. and B. Gaso (2005). "Organisational frameworks for listening post activities." Int. J. Technology Intelligence and Planning 1(3): 241-265.

Giuliani E., Bell M. (2004), "When micro shapes the meso: Learning networks in a Chilean wine cluster », SPRU Electronic Working Paper Series, Paper No. 115, April 2004

Granovetter M. S. (1985), Economic Action and Social Structure : The Problem of Embeddedness. American Journal of Sociology, vol. 91, $n^{\circ} 3$.

Granovetter, M. S. (1983). "The strength of weak ties: a network theory revisited." Sociological Theory 1: 201-233. 
He S. (2006), Clusters, structural embeddedness, and knowledge: A structural embeddedness model of clusters. DRUID-DIME Winter PhD Conference, Skoerping, Denmark.

Hervás-Oliver J. L. ; José Albors-Garrigós J. (2007), Do clusters capabilities matter? An empirical application of the resource-based view in clusters. Entrepreneurship \& Regional Development: An International Journal, Vol.19, $\mathrm{N}^{\circ} 2$

Hervás-Oliver J. L. ; José Albors-Garrigós J. (2008), Local knowledge domains and the role of MNE affiliates in bridging and complementing a cluster's knowledge. Entrepreneurship \& Regional Development: An International Journal, 1464-5114, Vol.20, Nº

Huggins, R. (2008). "The Evolution of Knowledge Clusters: Progress and Policy." Economic Development Quarterly 22(4): 277-288.

Keeble D., Wilkinson F. et al (2000) (eds.) High-Technology Clusters, Networking and Collective Learning in Europe. Aldershot: Ashgate.

Kerr, C. I. V., L. Mortara, et al. (2006). "A conceptual model for technology intelligence." International Journal of Technology Intelligence and Planning 1(2): 73-93.

Kogut, B. (2000), The Network as Knowledge: Generative Rules and the Emergence of Structure. Strategic Management Journal, Vol.21

Lazaric N., Longhi C. and Thomas C. (2008), Gatekeepers of knowledge versus platforms of knowledge: from potential to realized absorptive capacity, Regional Studies, Vol.42, Nº, pp. 837-852

Lazersona MH, Lorenzoni G. (1999), The firms that feed industrial districts: A return to the Italian source. Oxford University Press, Industrial and Corporate Change, Vol. 8, ํ2

Lee C.-K., Saxenian A.(2008), Coevolution and coordination: A systemic analysis of the Taiwanese information technology industry. Journal of Economic Geography, vol. 8

Lichtenthaler, E. (2003), Third generation management of technology intelligence processes." R\&D Management 33(4): 361-375.

Lichtenthaler, E. (2004), Technological change and the technology intelligence process: a case study. J. Eng. Technol. Manage. 21: 331-348.

Lichtenthaler, E. (2004), Technology Intelligence processes in leading European and North American multinationals." R\&D Management 34(2): 121-135.

Lichtenthaler, E. (2005), The choice of technology intelligence methods in multinationals: towards a contingency approach." International Journal Of Technology Management 32(3/4): 388-405.

Lichtenthaler, E. (2006), Technology Intelligence: identification of technological opportunities and threats by firms." International Journal of Technology Intelligence and Planning 2(3): 289-323. 
Lichtenthaler, E. (2007). "Managing technology intelligence processes in situations of radical technological change." Technological forecasting \& social change 74: 1109-1136.

Lundvall B.-A. (1992), National Systems of Innovation: Towards a Theory of Innovation and Interactive Learning. London: Pinter Publishers

Malmberg A., Maskell P. (2005), Localized Learning Revisited. Druid paper

Markusen A. (1996), Sticky Places in Slippery Space: A Typology on Industrial Districts. Economic Geography, Vol. 72

Marshall A. (1920), Principles of Economics, 8th edition., Macmillan, London, First edition [1891]

Maskell, P. (2001), Towards a Knowledge-based Theory of the Geographical Cluster. Industrial and Corporate Change, Vol. 10, No. 4

Maskell, P., Bathelt, H., Malmberg, A. (2006), Building global knowledge pipelines: the role of temporary clusters, European Planning Studies, vol.14

Minshall, T., L. Mortara, et al. (2007). Open innovation: Linking strategic and operational factors. R\&D Management Bremen, Germany.

Mortara, L., C. I. V. Kerr, et al. (2009). "A toolbox of elements to build technology intelligence systems." International Journal of Technology Management 47(4): 322-345.

Mortara, L., C. I. V. Kerr, et al. (2009). "Technology intelligence practice in UK technology-based companies." International Journal of Technology Management 48 (1): 115 -135.

Mortara, L., R. Thomson, et al. (2010a). "Implementing a Global Technology Sourcing Strategy -scan and target at Kodak European Research." Research - Technology Management (July-August).

Mortara, L., R. Thomson, T. Minshall and D. Probert (2010b). The 'social' dimension of technology intelligence: Approaches to intelligence through intermediary networks. The R\&D Management conference - Information, imagination and intelligence in R\&D management, Manchester, 30 June- 2 July 2010.

Nooteboom, B. (2005), Innovation, learning and cluster dynamics. Discussion Paper 44, Tilburg University, Center for Economic Research

Owen-Smith J. \& Powell W. (2004), Knowledge Network as Channels and conduits: The Effects of Spillovers in the Boston Biotechnology Community. Organization Science, Vol.15, N¹

Pecqueur B., Zimmermann J.B. (2004), L'économie de proximités. Paris : éditions Hermes-Lavoisier, 264 pages.

Powell W. W., Koput K.W., Smith-Doerr L. (1996), Interorganizational Collaboration and the Locus of Innovation: Networks of Learning in Biotechnology. Administrative Science Quarterly Vol. 41 
Powell, W. W., Kelley Packalen, and Kjersten Bunker Whittington (2010), Organizational and Institutional Genesis: The Emergence of High-Tech Clusters in the Life Sciences. Clusters, Networks, and Innovation, edited by John Padgett and W.W. Powell. Chapter 13. Princeton University Press

Rallet A., Torre A. (2005), Proximity and localization. Regional Studies, vol. 39, $n^{\circ} 1$

Rohrbeck, R. (2010). "Harnessing a network of experts for competitive advantage: technology scouting in the ICT industry." R \& D Management 40(2): 169-180.

Rychen F., Zimmermann J.B. (2006), Clusters in the global knowledge based economy: knowledge gatekeepers and temporary proximity, Regional Studies, Vol.42, №26

Savioz, P. (2006). "Technology Intelligence Systems: practices and models for large, medium-sized and start-up companies." international Journal of Technology Intelligence and Planning 2(6): 360379.

Savioz, P. and H. Tschirky (2004). Technology Intelligence Systems: benefits and roles of top management. Bringing technology and innovation into the boardroom. Strategy, Innovation and Competences for business value. New York, Palgrave Macmillan: 220-254.

Savioz, P. and M. Blum (2002). "Strategic forecast tool for SMEs: how the opportunity landscape interacts with business strategy to anticipate technological trends." Technovation 22(2): 91.

Smith J.O., Powell W.W. (2004), Knowledge Network as channels and Conduits: The Effects of Spillovers in the Boston Biotechnology Community. Organization Science, vol 15, $n^{\circ} 1$.

Sorenson O., Rivkin J.W., Fleming L. (2006), Complexity, Networks and Knowledge Flow. Research Policy, vol. $35, n^{\circ} 7$.

Stephenson, K. (1999). Networks. The Technology Management Handbook. R. C. Dorf. US, CRC Press IEEE Press: 7-40 to 47-45.

Storper M., Venables A.-J. (2003), Buzz: Face-To-Face Contact and the Urban Economy, Centre for Economic Performance, London School of Economics, Londres.

Uzzi, B. and S. Dunlap (2005), How to Build Your Network. Harvard Business Review. 53-60.

Waxell A.; Malmberg A. (2007), What is global and what is local in knowledge-generating interaction? The case of the biotech cluster in Uppsala, Sweden. Entrepreneurship \& Regional Development: An International Journal, 1464-5114, Vol.19, N²

Whittington B. K., Owen-Smith J., and Powell W. W. (2009), Networks, Propinquity and Innovation in Technological Communities. Administrative Science Quarterly, vol. 54.

Witzeman, S., G. Slowinski, et al. (2006). "Harnessing external technology for innovation." ResearchTechnology Management 49(3): 19-27. 